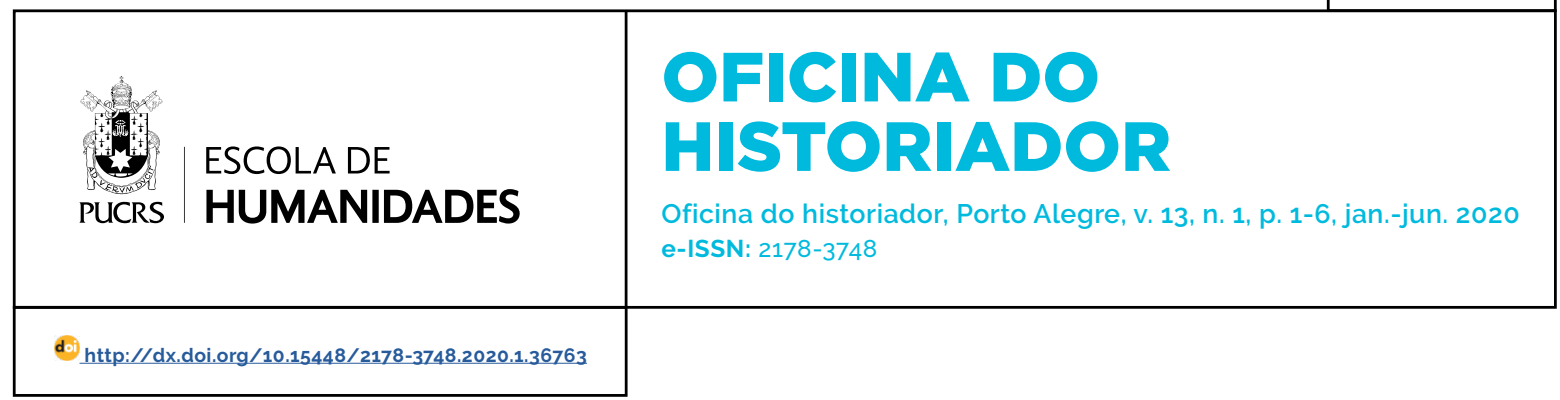

SEÇÃO: DOSSIÊ

\title{
A pesca e o pescador: por uma haliêutica historicizada
}

Fishing and fisherman: for a historic halieutic

\section{Gustavo Peretti \\ Wagner ${ }^{1}$ \\ orcid.org/0000-0002-0002-557X \\ gustavo.wagner@ufpel.edu.br}

Lucas Antonio da Silva ${ }^{2}$

orcid.org/0000-0001-7818-2973

las.arqueo@gmail.com

Recebido em: 6 jan. 2020.

Aprovado em: 3 fev. 2020.

Publicado em: 14 jun. 2020.

\section{(c) (1)}

Artigo está licenciado sob forma de uma licença Creative Commons Atribuição 4.0 Internacional.
Resumo: A pesca e o pescador são categorias construídas a partir de diferentes contextos históricos. A haliêutica (a arte da pesca), reúne diferentes pescadores, tralhas, fainas e saberes locais que conferem coesão social. Em linhas gerais, o que se propõe é compreender a formação das comunidades pesqueiras através dos elementos de coesão referidas, nestas comunidades a pesca é organizada por meio do conhecimento e território, sendo este central para a delimitação das práticas e das identidades que surgem a partir delas. O pescador se constitui enquanto tal, a partir das inúmeras relações que estabelece com seu território, com os seres e conhecimentos adquiridos nessa convivência.

Palavras-chave: Pesca. Pescador. Identidade. Território.

Abstract: Fishing and fisherman are categories constructed from different historical contexts. Halieutic (art of fishing), brings together different models of fishermen, fish, fishing and local knowledge that give social cohesion. In general, what is proposed is to understand the formation of fishing communities through the elements of cohesion mentioned, in these communities fishing is organized through knowledge and territory, which is central to the delimitation of practices and identities that arise from from them. The fisherman is constituted as such, from the innumerable relationships he establishes with his territory, with the beings and knowledge acquired in this coexistence.

Keywords: Fishing. Fisherman. Identity. Territory.

\section{Introdução}

A presente proposta de texto diz respeito à compreensão das diferentes estratégias pesqueiras desenvolvidas na costa leste do Brasil entendidas enquanto processos de longa-duração.

A faixa costeira brasileira se caracteriza pela diversidade de ambientes geomorfológicos abióticos que propiciam a fixação da fauna e flora dando origem a habitats subaquáticos de alta produtividade biótica. Estes ambientes são essenciais para a manutenção do modo de vida tradicional das populações litorâneas desde a pré-história e o impacto sobre esses ambientes acarreta uma série de transformações nos modos de vida nas esferas social, cultural e econômica (WAGNER; SILVA, 2014).

As haliêuticas tradicionais são resultado das interações das diferentes populações com os ambientes costeiros, sejam eles lagunas, lagos, estuários, baías ou "mar raso", dando origem a múltiplas técnicas e equipamentos. A influência da colonização europeia e africana iniciada no século XVI impactou sobremaneira as atividades pesqueiras tradicionais, proporcionando a introdução de equipamentos, técnicas e conhecimentos novos à milenar haliêutica indígena brasileira. 


\section{Pré-história da pesca}

Precisar o surgimento da prática da pesca é um desafio apenas superável pela Arqueologia. Os mais antigos registros materiais da pesca no continente sul-americano remontam ao Pleistoceno Final, indicando que as técnicas de exploração dos recursos aquáticos acompanharam os primeiros colonizadores, seja por rotas marinhas ou terrestres. No hemisfério pacifico da América do Sul as culturas pesqueiras especializadas remontam a 12 mil anos, na costa peruana e chilena. No Brasil, as evidências mais antigas localizam-se em sítios de populações caçadoras-coletoras do interior, com datas que se situam no Holoceno Inicial. Na Amazônia, ossos de peixes de pequeno porte são encontrados nas camadas estratigráficas de base do Abrigo da Pedra Pintada com cronologia de 11.300 A.P. No Planalto Central brasileiro anzóis confeccionados sobre diáfises de mamiferos terrestres surgem já a partir de 9.500 B.P. Contudo a especialização do modo de vida pescador ocorreu apenas na entrada do Holoceno Médio com as ocupações iniciais dos sambaquis e sítios concheiros na costa sudeste há 8.000 anos A.P. A identificação da ictio-fauna predada pelos pescadorescoletores dos sambaquis evidencia o impacto especifico sobre as áreas lagunares e estuarinas. Nestes sitios os anzóis apresentam tipologia mais variada e são acompanhados por pesos de rede e linha confeccionados em pedra polida. Os sítios arqueológicos das populações agricultoras Guarani do sul do Brasil demonstram um padrão de assentamento claramente voltado para a exploração de recursos aquáticos e caracterizam a continuidade das atividades, mas com o deslocamento dos impactos para as áreas lacustres e fluviais costeiras. Os dados etno-históricos do século XVI revelam que as sociedades Tupi costeiras possuiam elevado grau de apropriação dos ambientes aquáticos e desenvolveram intensas atividades pesqueiras manejando venenos de origem vegetal e dando origem ao que conceitua-se "haliêuitica indígena tradicional". A disseminação do uso de embarcações permitiu a criação de amplas redes de influência política e bélica baseadas nas relações de parentesco e reciprocidade. Contudo, são recorrentes na literatura as beligerâncias causadas pela disputa de áreas de pesca, principalmente na região sudeste, onde o domínio sobre a pesca intensiva da tainha (Mugilidae) em piracema (termo Tupi para o período de desova) é item de maior cobiça Tupinambá.

\section{Haliêutica historicizada}

Desde os anos finais do século XIX que a pesca artesanal tornou-se foco de estudos especificos, embora esporádicos. Verissimo (1970, Lopes (1938), Willems (2003[1952]) e CâmaraCascudo (2002), retrataram de forma apaixonada um pescador idilico, senhor do mar e patrono de uma sabedoria carregada de empirismo e eficiência3. Fazem parte deste perido os estudos sobre a marcenaria náutica indiana desenvolvida pelos artesãos trazidos do Oriente pela Coroa Portuguesa para os estaleiros da Bahia e Rio de Janeiro (ALVES-CÂMARA, 1976).

A partir de meados dos anos 1960 e especialmente na década de 1970 , as pesquisas pulverizaram-se compreendendo quase todo o litoral brasileiro (KOTTAK, 1966; FORMAN, 1970; MOURÃO 2003; DIEGUES, 1973; LIMA, 1978; DUARTE, 1978; BECK, 1979). A partir de então, o pescador passa a ser retratado como um camponês do mar, um sobrevivente cujo modo de vida estava pressionado entre o calendário agrícola de pequeno produtor familiar e a crescente mecanização da pesca industrial mercantil. As décadas que se seguiram marcam o surgimento da socioantropologia da pesca e consolidam um campo de pesquisa onde as abordagens e temas de pesquisa multiplicam-se ao longo de todo o Pais (DIEGUES, 1973, 1997, 1998, 1999, 2000, 2004; FURTADO, 1897; MALDONADO, 1994, 2000; BEGOSSI, 2004; CASTELLUCCI, 2008).

No Sul do Brasil as pesquisas filológicas empreendidas nas décadas iniciais do século

3 Diegues (1997) sugere que os estudos realizados nas décadas de 1950 e 1960 sejam englobados no periodo dos estudos do folclore brasileiro. 
XX demonstraram a preponderância de vocábulos de origem Bantu para designar equipamentos de pesca (LAYTANO, 1995).

Enquanto fenômeno social a haliêutica traduz atividades produtivas e relações simbólicas no âmbito da vida cotidiana. As atividades produtivas dependem dos saberes técnicos tradicionais relativos, basicamente à confecção e ao manuseio dos equipamentos e das embarcações, mas também de uma série de conhecimentos não expressos materialmente. A mestrança éa categoria que reúne tais pré-requisitos, incorporando as noções de espacialidade, marcação e domínio dos territórios e pesqueiros, domínio sobre a meteorologia, bem como a navegação, seja de mar ou de costa (águas costeiras interiores). No cotidiano das atividades são estabelecidas e expressas, por um lado, as relações identitárias e de pertença e, por outro, é construído e vivido o universo simbólico do mundo da pesca. É necessário atentar para a distinção entre dois diferentes tipos de pescadores. Há aqueles pescadores cuja subsistência está relacionada às águas profundas, cuja interação com o mar se dá prioritariamente em mar aberto, na pesca de dormida, onde passam dias sem retornar a terra, sejam eles artesanais ou mecanizados. Esses pescadores são marcados pela incerteza, pelo risco, suscetíveis à meteorologia e à força do mar. De outra parte, há aqueles pescadores que vivem em terra, atrelados a um complexo calendário de plantio e colheita, onde a pesca assume caráter litorâneo, sendo realizada principalmente emáguas abrigadas ou no mar raso, perto da costa. Mas falta a esses pescadores uma relação mais intima com o oceano, expressa sob o termo "ideologia de pesca". Destaca-se nesse sentido, a dicotomia entre comunidades maritimas e comunidades costeiras, embora sejam errôneas as abordagens que as compreendam antagonicamente. Essas duas categorias personalizam, na realidade, o acesso e a adoção intencional das tecnologias de pesca e, sobretudo, de navegação, produzindo impactos diferenciados nos ambientes explorados, impactos estes que devem ser avaliados in loco. É precisamente esse o desafio final desta proposta de trabalho.

\section{A conquista do "mar de fora"}

A conquista do "mar de fora" foi possivel apenas através da introdução de técnicas europeias de navegação. Mourão (2003), Diegues (1973), Lima (1978) e Duarte (1978), deixaram clara a tendência geral existente para a pesca capixaba de que o "mar de fora" passou a ser foco produtivo apenas após a introdução dos motores a diesel e a possibilidade de manter resfriado o pescado. Mourão (2003) chega a definir um conceito-chave para a socioantropologia da pesca: "a ideologia de pesca", presente apenas no pescador de alto mar, praticante da pesca de dormida.

Câmara-Cascudo (2002) descreve vividamente a pesca e a navegação dos jangadeiros no Nordeste do Brasil. Naquela navegação, o atrelamento da vela latina às jangadas e pirogas Tupinambá se deu já no século XVII, permitindo alcançar pesqueiros a grandes distâncias da costa. A autonomia garantida pela propulsão dos ventos permitiu a "marcação das pedras" de fundo pelos mestres pescadores até a quebra da plataforma continental na transição para o oceano profundo, centenas de quilômetros mar adentro, conhecida há séculos como "o barranco". Estaria em MarcGraf (1648 apud CÂMARA-CASCUDO, 1854) a primeira descrição da autonomia desta navegação avistada cruzando o caminho das naus europeias na rota das navegações.

\section{Comunidades de pesca}

As comunidades de pescadores no Brasil são um fenômeno que se desenvolveu, em sua maioria ${ }^{4}$, vinculadas à exploração do ambiente costeiro (GASPAR et al., 2008). Nesse sentido, tal como propõe Diegues (1997, 2004), as comunidades costeiras, caracterizadas como grupos de pescadores que utilizam e/ou se apropriam dos ambientes aquáticos costeiros ou do "mar raso", foram, pelo

4 Figuti et al. (2013) destacam a existência de ocupações pescadoras-coletoras em sambaquis estuarinos. As datações são próximas dos 10 mil A.P no Vale do Ribeira, em São Paulo. 
menos até meados do século XIX, a única forma de exploração pesqueira no litoral brasileiro. A partir da utilização de grandes embarcações e da mecanização da pesca, fenômeno tardio no Brasil (DIEGUES, 1997, 1999, 2004), é que se nota o desenvolvimento das comunidades maritimas, ou seja, aquelas que utilizam os recursos do mar profundo ou "mar de fora".

Essas comunidades costeiras possuem uma relação profunda com o ambiente à sua volta, caracterizada, sobretudo, pela tradição e no conhecimento adquirido na convivência com estes locais. Tal como destaca Diegues (1999, 2004) esta tradição se baseia na longa continuidade temporal da pesca artesanal, no dominio do "saber-fazer", da "arte"5 que envolve a pesca e nos conhecimentos adquiridos e herdados dos pescadores mais velhos. De modo geral, esse conhecimento tradicional se constrói na vivência com os mestres e com o território criando imagens e conceitos sobre o ambiente que o circunda. Mais do que uma questão produtiva, os pescadores estabelecem relações de vida com esses locais (SILVA, 2015). Sendo assim, esses espaços se caracterizam como parte importante no desenvolvimento do modo de vida pescador nos seus mais diversos aspectos, desde o conhecimento dos hábitos dos peixes, dos locais de pesca, da movimentação dos ventos, das visões e percepções que estes constroem de seu território (ADOMILLI, 2002, 2007: DIEGUES, 1997, 2004; MALDONADO, 1994. 2000; SILVA, 2012, 2018; SILVA; GASPAR, 2019)

O conhecimento tradicional pode ser caracterizado como uma habilidade repassada através da reprodução da experiência, da observação dos mais velhos e, principalmente, através da oralidade nos ambientes de sociabilidade. O papel desempenhado pelo mestre enquanto condutor da embarcação e da própria pescaria, assume posição de destaque na mestrança, pois ele é o personagem que detém a experiência necessária para a superação eficaz dos desafios que as instáveis águas das lagoas, estuários ou mar encerram. Da mesma forma, é dele a responsabilidade de repassar aos mais jovens a mestrança necessária para o sucesso da pesca, perpetuado nas práticas cotidianas.

Já o território, tal como propõe Begossi (2004), Diegues (1997, 1998, 2000, 2004) e Maldonado (1994), se caracteriza por uma porção do meio físico e do espaço sobre o qual uma determinada sociedade reivindica o controle ou uso dos recursos existentes nesse local. Esse território, além de fornecer os meios para subsistência, é caracterizado pela materialização das relações sociais de uma determinada sociedade e, ao mesmo tempo, pela imaterialidade das representações que cada grupo possui desses espaços. Sendo assim, o conceito de território tanto pode estar relacionado a uma realidade geográfica, quanto às representações sobre estas. Tal como visto anteriormente, se o conhecimento tradicional auxilia na manutenção do território pode-se afirmar que território também é conhecimento. Portanto, territórios são usados, defendidos e pensados.

Observa-se, portanto, que o conhecimento tradicional se encontra relacionado à construção do território. Sendo este composto por questões produtivas, pela materialização de relações sociais e pela imaterialidade das representações simbólicas que cada grupo constrói sobre seu território (BEGOSSI, 2004; DIEGUES, 1997, 1998, 2000, 2004; MALDONADO, 1994, 2000). Diante disso, entende-se que essas variáveis atuam de maneira indissociável na construção do território ${ }^{6}$.

Em linhas gerais, a formação das comunidades pesca encontra-se diretamente ligada à produção do conhecimento e do território. Na relação mútua entre o saber e o lugar o pescador se constitui enquanto tal, a partir das inúmeras relações que estabelece com seu território, com os seres e conhecimentos adquiridos nessa convivência, portanto, essa indissociabilidade do ser, do lugar e do conhecer encontra-se materializada na formação das comunidades de pesca de um modo geral. Com isso, concluindo a partir de 
uma leitura arqueológica, pode-se afirmar que a materialidade da vida do pescador é parte fundamental para articular o pescador, com seus lugares e conhecimentos.

\section{Considerações finais}

As sociedades pescadoras da costa leste brasileira possuem uma longa trajetória de vida vinculada à exploração, uso e apropriação dos espaços aquáticos, sejam eles do mar aberto, da costa ou águas interiores. Como já referido, os dados arqueológicos demonstram que essa relação com os diversos espaços aquáticos possui uma profundidade temporal, colocando em evidência a persistência do modo de vida pesqueiro relacionados a estes locais.

Por conseguinte, a formação dessas comunidades pesqueiras possui elementos comuns tais como, o uso, a apropriação e o conhecimento dos territórios. A socioantropologia da pesca demonstrou que território e conhecimento estão no centro das práticas relacionadas às comunidades de pescadores de modo geral. Essa centralidade decorre das questões produtivas e simbólicas e, somadas, constituem parte fundamental da identidade do pescador.

As historicidades, os territórios, os conhecimentos e as identidades atuam conjuntamente na constituição da arte da pesca - haliêutica. Ao observar os diferentes grupos de pescadores que viveram e vivem na costa brasileira pode-se afirmar que o modo de vida relacionado às águas e aos peixes se constituiu na associação entre os elementos suprarreferidos.

Com isso, entende-se que é preciso seguir ampliando as pesquisas relacionadas às comunidades pesqueiras sob uma perspectiva material. A arqueologia pode contribuir para esse debate lançando interpretações sobre a materialidade da pesca, analisando as relações entre sujeitos, coisas e territórios. Independente da temporalidade, seja com os pescadores coletores dos sambaquis, ou pescadores das comunidades recentes, pode-se traçar inúmeros paralelos e semelhanças relacionadas a este modo de vida e de ser pescador.

\section{Referências}

ADOMILLI, Gianpaolo. Trabalho, meio ambiente e conflito: um estudo antropológico sobre a construção da identidade social dos pescadores do Parque Nacional da Lagoa do Peixe - RS. 2002. Dissertação (Mestrado em Antropologia Social) - Instituto de Filosofia e Ciências Humanas, Universidade Federal do Rio Grande do Sul, Porto Alegre, 2002.

ADOMILLI, Gianpaolo. Terra e mar, do viver e do trabalhar na pesca maritima: tempo, espaço e ambiente junto a pescadores de São José do Norte - RS. 2007. Tese (Doutorado em Antropologia Social) Instituto de Filosofia e Ciências Humanas, Universidade Federal do Rio Grande do Sul, Porto Alegre, 2007.

ALVES-CÂMARA, Antônio. Ensaio sobre as construções navais indigenas do Brasil. São Paulo: Brasiliana, 1976 [1888].

BECK, Anamaria. Lavradores e Pescadores: um estudo sobre trabalho familiar e trabalho acessório. Monografia (Livre Docência - Professor Titular) - UFSC, Florianópolis, 1979.

BEGOSSI, Alpina. Áreas, Pontos de Pesca, Pesqueiros e Território na Pesca Artesanal. In: BEGOSSI, A. (org.). Ecologia de Pescadores da Mata Atlântica e da Amazônia. São Paulo: NUPAUB-USP, 2004. p. 223-255.

CÂMARA-CASCUDO, Luís. Jangada: uma pesquisa etnográfica. São Paulo: [s. n.], 2002 [1954].

CASTELLUCCI, Wellington. Pescadores e roceiros: escravos e forros em Itaparica na segunda metade do século XIX, 1860-1888. São Paulo: Annablume, 2008.

DIEGUES, Antônio Carlos. Pesca e Marginalização no Litoral Paulista. 1973. Dissertação (Mestrado em Ciências), FFLCH, Universidade de São Paulo, São Paulo, 1973.

DIEGUES, Antônio Carlos. Tradition and change in brazilian fishing communities: towards a social anthropology of the sea. In: DIEGUES, A. (org). Tradition and social change in the coastal communities of Brazil. São Paulo, NUPAUB, 1997. p. 1-24

DIEGUES, Antônio Carlos. Ithas e Mares. Simbolismo e Imaginário. São Paulo: Hucitec, 1998. 272p.

DIEGUES, Antônio Carlos. A sócio-antropologia das comunidades de pescadores maritimos do Brasil: uma sintese histórica. São Paulo, NUPAUB, 1999.

DIEGUES, Antônio Carlos (org.) A imagem das águas. São Paulo: Hucitec/NUPAUB-USP, 2000.

DIEGUES, Antônio Carlos. A Pesca Construindo Sociedades. São Paulo: NUPAB - USP, 2004.

DUARTE, Fernando. As redes do suor: a reprodução social dos trabalhadores da produção do pescado em Jurujuba. Rio de Janeiro. 1978. Dissertação (Mestrado Antropologia Social) - Museu Nacional, Universidade Federal do Rio de Janeiro, Rio de Janeiro, 1978.

FIGUTI, Levy; et al. Small sambaquis and big chronologies: shellmound building and hunter-gatherers in neotropical highlands. Radiocarbon 55, p. 1215-1221, 2013. https://doi.org/10.1017/S0033822200048128 
FORMAN, Shepard. The Raft Fishermen: Tradition and Change in the Brazilian Peasant Economy. EUA, Indiana University Press, 1970.

FURTADO, Lourdes. Curralistas e redeiros de Marudá pescadores do litoral do Pará. Belém: Museu Paraense Emilio Goeldi, 1987.

GASPAR, Maria Dulce et al. Sambaqui (Shell Mound) Societies of Coastal Brazil. In: SILVERMAN, Helaine.; ISBEL, William. (ed.). Handbook of South América Archaeology. 1ed. Lisboa: Springer, 2008. p. 319-335. https://doi.org/10.1007/978-0-387-74907-5_18

KOTTAK, Conrad. The Structure of Equality in Brazilian Fishing Community. Columbia, Univ. Press 1966.

KOTTAK, Conrad. An Assault on Paradise. Michigan, Ann Arbor Univ. of Michigan Press. 1983

LAYTANO, Dante. (org.). O negro no Rio Grande do Sul. In: Estudos Ibero Americanos, Porto Alegre, v. 21, n. 2, p. 187-201, 1995. https://doi.org/10.15448/ 1980-864X.1995.2.28832

LIMA, Roberto. Pescadores de Itaipu: a pescaria da tainha e a produção ritual da identidade social. Rio de Janeiro: Museu Nacional, 1978.

LOPES, Raimundo. Pesquisa Etnológica sobre a Pesca Brasileira no Maranhão. Revista do Serviço do Patrimônio Histórico e Artístico Nacional, Rio de Janeiro, n. 2, p. 51-86, 1938.

MALDONADO, Simone. Mestres e Mares, espaço e indivisão na pesca maritima. $2^{\circ}$ ed. São Paulo: Annablume, 1994.

MALDONADO, Simone. O caminho das pedras: percepção e utilização do espaço marinho na pesca simples. In: DIEGUES, A. C (org). A imagem das águas São Paulo: Hucitec/NUPAUB-USP, 2000. p. 59-68.

MOURÃO, Fernando. Pescadores do litoral sul do Estado de São Paulo. São Paulo: Hucitec/NUPAUB-USP, 2003[1971]. 264 p.

SILVA, Lucas. Pescadores da Barra do João Pedro, um estudo etnoarqueológico. 2012. Dissertação (Mestrado em História) Instituto de Filosofia e Ciências Humanas, Pontifícia Universidade Católica do Rio Grande do Sul, Porto Alegre, 2012.

SILVA, Lucas. Com vento a lagoa vira mar: uma etnoarqueologia da pesca no litoral norte do RS. Boletim do Museu Paraense Emilio Goeldi. Ciências Humanas, Belém, v. 10, n. 2, p. 537- 547, maio-ago. 2015

SILVA, Lucas. Os materiais de pesca fluindo. Uma arqueologia com os pés na água. 2018. Tese (Doutorado em Arqueologia) - Museu Nacional, Universidade Federal do Rio de Janeiro, Rio de Janeiro, 2018.

SILVA, Lucas; GASPAR, Madu. Anzóis, redes e pescadores: reflexões sobre a arqueologia da pesca. Revista de Arqueologia, v. 32, n. 2, Edição especial Museu Nacional (v. 1), p. 4-15, 2019. https://doi. org/10.1590/1981-81222015000200016.

VERÍSSIMO, José. A pesca na Amazônia. Belém: Universidade Federal do Pará, 1970[1895]. 130p.
WAGNER, Gustavo; SILVA, Lucas. Prehistoric maritime domain and Brazilian shellmounds. Archaeological Discovery, v. 2, n.1, p. 1-5, Jan. 2014. https://doi. org/10.4236/ad.2014.21001

WILLEMS, Emilio. A llha de Búzios: uma comunidade Caiçara no Sul do Brasil. São Paulo: HUCITEC, 2003[1952]. 185p.

\section{Gustavo Peretti Wagner}

Doutor em História pela Pontifícia Universidade Católica do Rio Grande do Sul - PUCRS. Docente do Departamento de Antropologia e Arqueologia da Universidade Federal de Pelotas - UFPel.

\section{Lucas Antonio da Silva}

Doutor em Arqueologia pela Universidade Federal do Rio de Janeiro (UFRJ, Rio de Janeiro, RJ, Brasil). Bolsista de pós-doutorado do Programa de Pós- Graduação em História da Pontifícia Universidade Católica do RS (PUCRS, Porto Alegre, RS, Brasil).

\section{Endereço para correspondência}

Gustavo Peretti Wagner

Universidade Federal de Pelotas

Rua Gomes Carneiro, 01

Balsa, 96010-610

Pelotas, RS, Brasil

Lucas Antonio da Silva

Pontifícia Universidade Católica do Rio Grande do Sul Av. Ipiranga, 6681, Prédio 40

Partenon, 90619-900

Porto Alegre, RS, Brasil 